\title{
Studying the Status of Internet Addiction among High School Students in the Southeast of Iran: A Descriptive Study
}

\author{
Ali Akbar Nasiri ${ }^{1}$, Abbas Balouchi ${ }^{2}$, Hosein Shahdadi ${ }^{3}$ \\ ${ }^{1}$ Faculty of Medicine School, Department of Anesthesiology and Pain Medicine, \\ School of Medicine, Zabol University of Medical Science, IR Iran \\ ${ }^{2}$ MSc Student of Nursing, , Student Research Committee (SRC), School of Nursing and Midwifery, \\ Zabol University of Medical Sciences (zbmu), Zabol, IR Iran \\ ${ }^{3}$ MSc in Nursing, Department of Medical Surgical, School of Nursing and Midwifery, \\ Zabol University of Medical Sciences, Zabol, IR Iran
}

\begin{abstract}
Introduction: Internet addiction is one of the major problems of the modern world that has involved all walks of life and especially students. Studying the rate and the way of dealing with this problem seems to be necessary. Methods: This cross-sectional, descriptive study was carried out on a sample of 190 high school students (out of 210) in Nikshahr, a town in southeast of Iran, from November 2014 to May 2015. The participants were selected using the simple random sampling method. The only inclusion criterion was voluntary and conscious consent. The required data were collected using a standard questionnaire consisting of two parts of demographic information (age, gender, and educational grade) and Standard Young's Internet Addiction Test that its validity and reliability had been previously demonstrated in various studies. The data were statistically analyzed in SPSS-22 software. Results: The rate of answering to questions was $90 \%$. According to the results, the mean and standard deviation of participants'age was $17.9 \pm 2.1$ and most of them were in the range of 12-19. Girls accounted for the majority of participants (109 students, 57.4\%). In terms of educational grade, most of participants (68 students, $35.8 \%$ ) were studying in the third grade of high school. Mean score of Internet addiction for the studied sample was obtained 70.2, reflecting an intense reliance on the Internet. Most participants (98 students, 51.1\%) had an intense reliance on the Internet. Conclusion: Given the superiority of prevention over treatment and considering the fact that Internet addiction is a health problem for the younger generation and the future-builders of a society, taking measures such as training the students and adolescents on correct use of the Internet and increasing the information and awareness of patents about computer and the Internet for exercising proper supervision and restriction on their children seems to be necessary.
\end{abstract}

Keywords: Internet addiction; Students; Iran

\section{Introduction}

Addiction (dependence) to the internet, as to mean the excessive use of the Internet in a way that would cause dysfunction, was firstly discussed by Young (1996) (1). In Iran, the Internet is becoming more and more pervasive day by day and this has made psychologists to pay a special attention to the excessive use of this technology. The concept of addiction, which actually means the physical dependence on a substance, has been also used for excessive use of the Internet. This term was firstly introduced by Goldberg in 1996. (2). The symptoms of Internet addiction include preoccupation with the Internet at all times, spending too much time on using the Internet instead of communicating with family members, using the Internet to escape from negative feelings such as depression and low self-esteem, weight gain, poor health, carpal tunnel disorder, and other physical problems (3). In addition, reduced academic performance is another symptom of Internet addiction, particularly among students (4). Students are considered among vulnerable groups because they are more willing to use the Internet due their plenty of free time every day (5).

Kaplan and Sadouk define Internet addiction as impulse control disorder and obsession with the Internet. In their opinion, people are not able to resist against the strong desire for using computer or surfing the net. There are several factors that predispose the occurrence of such addition (6).

Researchers who have studied the effects of the Internet on students argue that a small percentage of students (less than $5 \%$ ) may suffer from its harmful outcomes such as sleep disorders and depression, although most of people in society suffer form social isolation, depression, loneliness, and loss of time caused by Internet addiction (7). Studies show that Internet addiction rate is between $0.3 \%$ and $38 \%(8,9)$. A descriptive studied conducted on 2257 students in England showed that $3.2 \%$ of them were addicted to the Internet (3).

The results of a study conducted by V Fisoun, et al. showed that more than $64 \%$ of students suffer from Internet addiction. The results of a study conducted in Malaysia show the weekly hours of using the Internet from 4 hours in 2005 reached 28 hours in 2008 (10).Students mainly use the Internet for communicating with their friends and family members The use of Internet among high school students has significantly increased in recent years, as the Internet is today considered part of students' daily life. Using the Internet can be an opportunity for communication with friends, education, and research (11) An online survey showed that $68 \%$ of parents, $69 \%$ of students, and $69 \%$ of teachers believe that using the Internet could improve the academic status of students (ATT1998). On the other hand, using the Internet causes student 


\section{International Journal of Science and Research (IJSR) \\ ISSN (Online): 2319-7064}

Index Copernicus Value (2013): 6.14 | Impact Factor (2014): 5.611

to face different cultures and experience various social interactions. It also can cause a disruption in academic performance. According to the results of a study carried out in the US, $19.7 \%$ of students believed that using the Internet negatively affect their academic performance (12). Since few studies have been conducted on this subject in Iran and given the importance of this group of people in the future of the country, the present research aims to study the status of Internet addiction among high school students in southeast of Iran.

\section{Methods}

This cross-sectional, descriptive study was conducted on a sample of 190 high school students (out of 210) in Nikshahr, a town in southeast of Iran, from November 2014 to May 2015. The participants were selected using the simple random sampling method. The only inclusion criterion was voluntary and conscious consent. The required data were collected using an author-made questionnaire which was developed by using the comments and views of the experts in this field (1-3). This questionnaire consists of two parts of demographic information (age, gender, and educational grade) and Standard Young's Internet Addiction Test that its validity and reliability had been previously demonstrated in various studies. The data were statistically analyzed in SPSS-22 software. Developed by Kimberley Young in 1998, Young's Internet Addiction Test has 20 items and its scoring is based on Likert's 5-point scale (Rarely: 1, sometimes: 2, often: 3, most times: 4, Always: 5). The minimum and maximum score obtainable on this test are 20 and 100 , respectively. Based on the scores obtained on this test, subjects are divided into three groups of ordinary user (2049), mil addiction (50-79), and severe addiction (80-100) (4).

After coordination with Zainabiyya High School of Nikshahr, the researcher participated in classrooms in person and briefed the students on the research objectives. In order to increase the reliability of data, questionnaires were handed out among the students in the presence of the examiner and they were given 10 minutes to fill out them. Before the start of the study, all participants were briefed on the research procedure and they were assured that their name and personal information will be kept confidential. A written informed consent was obtained from all participant and all of them were given the right to leave the study any time they want. The data were statistically analyzed in SPSS-22 software. To describe the data, descriptive statistical indices such as frequency, frequency percentage, mean, and standard deviation were used. Chi-square test was used in order to study the relationship between the way of getting familiar with the Internet, the social networks having a profile in, and the reasons for using the social networks in the case and control groups. In addition, independent t-test was applied for studying the relationship between the time spent on using computer, the Internet, and the social networks in the case and control groups. Statistical confidence interval and level of significance were determined to be $95 \%$ and $<0.05$, respectively.

\section{Results}

The rate of answering to questions was $90 \%$. According to the results, the mean and standard deviation of participants' age was $17.9 \pm 2.1$ and most of them were in the range of 12 19. Girls accounted for the majority of participants (109 students, 57.4\%). In terms of educational grade, most of participants (68 students, 35.8\%) were studying in the third grade of high school (Table 1).

Table 1: Demographic information

\begin{tabular}{|c|c|}
\hline Demographic information & Mean \pm SD \\
\hline age & $17.9 \pm 2.1$ \\
\hline & $\mathrm{N}(\%)$ \\
\hline Gender & $81(42.6 \%)$ \\
Boy & $109(57.4 \%)$ \\
Girl & $34(17.9 \%)$ \\
1 & $67(35.3 \%)$ \\
2 & $68(35.8 \%)$ \\
3 & $21(11.1 \%)$ \\
\hline
\end{tabular}

Mean score of Internet addiction for the studied sample was obtained 70.2, reflecting an intense reliance on the Internet. Most participants (98 students, 51.1\%) had an intense reliance on the Internet (Table 2).

Table 2: The rate of dependence on the Internet among the studied students

\begin{tabular}{|c|c|}
\hline Level of dependence on the Internet & Score \\
\hline Mild & $54(28.4 \%)$ \\
\hline Moderate & $38(20 \%)$ \\
\hline Intense & $98(51.1 \%)$ \\
\hline
\end{tabular}

Chi-square test results did nor show a statistically significant relationship between demographic characteristics and level of dependence on the Internet $(\mathrm{p}>0.05)$

\section{Discussion}

Most participants were highly dependent on the Internet, showing less frequency compared to the study of D SK Park (13) but higher frequency than studies of LSM Whang (14). In the present study, no significant relationship was found between age and Internet addiction, while such a relationship has been reported by other studies and the likelihood of addiction in adolescence was believed to be higher $(15,16)$. In the present study, frequency of Internet addiction was lower because the university students have passed their adolescence. In addition, the addicted users believed that life without the Internet is something Boring, fruitless, and without joy. This may be due to the prevalence of depression in this group. This relationship has been also observed in other studies (17). $10 \%$ of students believed that they experienced an academic failure because of the Internet, which is consistent with other studies (18). For resolving this problem, some measures should be taken. There is an inverse relationship between conscientiousness and internet addiction. This means that the Internet addiction score decreases with the increase in the score of conscientiousness and vice versa. This is consistent with the findings of $\mathrm{T}$ Durkee, 2012(19) indicating that Internet addicts are 


\section{International Journal of Science and Research (IJSR) \\ ISSN (Online): 2319-7064 \\ Index Copernicus Value (2013): 6.14 | Impact Factor (2014): 5.611}

wayward and willful, show paranoid states, and are weak in impulse control. Conscientiousness includes two main characteristics; the ability to control impulses and desires, and application of plans and programs in order to achieve the desired goals. A conscientious person has predetermined goals. Such people are successful, precise, punctual, and reliable in professional and academic fields. By contrast, unconscientiously persons have features such as dull fussiness and lack of adherence to moral principles. These people usually do not show sufficient accuracy in doing their duties and are not consistent for achieving their objectives. Therefore, it is natural that such people are more likely to be afflicted with the internet addiction, because if one does not have the necessary control over themselves, the Internet can easily attract them. According to A Weinstein,2010 the social networks such as Facebook can take a lot of time of people who obtain lower scores on the personality trait of conscientiousness, because they cannot control the time they spent on using these social networks (20).

\section{Conclusion}

Given the superiority of prevention over treatment and considering the fact that Internet addiction is a health problem for the younger generation and the future-builders of a society, taking measures such as training the students and adolescents on correct use of the Internet and increasing the information and awareness of patents about computer and the Internet for exercising proper supervision and restriction on their children seems to be necessary.

\section{Constraints}

One of the constraints of the present study was the small volume of the sample which cannot represent the whole Iranian students. Another constraint was the self-reporting approach chosen for filling out the questionnaire by students. If this done in an interview, it would produce better results. It is recommended that future studies focus on the barriers to the proper use of social networks among the students.

\section{Acknowledgements}

The authors would like to thank Ms. Derazehi, the Schoolmaster of Zainabiyya High School of Nikshahr.

\section{References}

[1] Young KS. Internet addiction: symptoms, evaluation and treatment. Innovations in clinical practice: A source book. 1999;17:19-31.

[2] Goldberg I. Internet addiction disorder. Retrieved November. 1996;24:2004.

[3] Beavers L, Bell RL, Choudhury D, Guyot W, Meier RJ. Online Time and Gender Perceptions of Internet Addiction. Journal of Higher Education Theory and Practice. 2015;15(3).

[4] Young KS. Internet addiction: The emergence of a new clinical disorder. CyberPsychology \& Behavior. 1998;1(3):237-44.
[5] Gainsbury S, Blaszczynski A. A systematic review of Internet-based therapy for the treatment of addictions. Clinical psychology review. 2011;31(3):490-8.

[6] Ko C-H, Hsiao S, Liu G-C, Yen J-Y, Yang M-J, Yen CF. The characteristics of decision making, potential to take risks, and personality of college students with Internet addiction. Psychiatry research. 2010;175(1):1215.

[7] Brenner V. Psychology of computer use: XLVII. Parameters of Internet use, abuse and addiction: the first 90 days of the Internet Usage Survey. Psychological reports. 1997;80(3):879-82.

[8] Johansson A, Götestam KG. Internet addiction: characteristics of a questionnaire and prevalence in Norwegian youth (12-18 years). Scandinavian journal of psychology. 2004;45(3):223-9.

[9] Pallanti S, Bernardi S, Quercioli L. The Shorter PROMIS Questionnaire and the Internet Addiction Scale in the assessment of multiple addictions in a high-school population: prevalence and related disability. CNS Spectr. 2006;11(12):966-74.

[10]Fisoun V, Floros G, Siomos K, Geroukalis D, Navridis $\mathrm{K}$. Internet addiction as an important predictor in early detection of adolescent drug use experienceimplications for research and practice. Journal of Addiction Medicine. 2012;6(1):77-84.

[11] Chou C, Condron L, Belland JC. A review of the research on Internet addiction. Educational Psychology Review. 2005;17(4):363-88.

[12] Hall AS, Parsons J. Internet addiction: College student case study using best practices in cognitive behavior therapy. Journal of mental health counseling. 2001;23(4):312.

[13] Park SK, Kim JY, Cho CB. Prevalence of Internet addiction and correlations with family factors among South Korean adolescents. Adolescence. 2008;43(172):895.

[14] Whang LS-M, Lee S, Chang G. Internet over-users' psychological profiles: a behavior sampling analysis on internet addiction. CyberPsychology \& Behavior. 2003;6(2):143-50.

[15] Young KS, Rogers RC. The relationship between depression and Internet addiction. CyberPsychology \& Behavior. 1998;1(1):25-8.

[16] Fu K-w, Chan WS, Wong PW, Yip PS. Internet addiction: prevalence, discriminant validity and correlates among adolescents in Hong Kong. The British Journal of Psychiatry. 2010;196(6):486-92.

[17] Kuss DJ, Van Rooij AJ, Shorter GW, Griffiths MD, van de Mheen D. Internet addiction in adolescents: Prevalence and risk factors. Computers in Human Behavior. 2013;29(5):1987-96.

[18] Jelenchick LA, Becker T, Moreno MA. Assessing the psychometric properties of the Internet Addiction Test (IAT) in US college students. Psychiatry Research. 2012;196(2):296-301.

[19] Durkee T, Kaess M, Carli V, Parzer P, Wasserman C, Floderus B, et al. Prevalence of pathological internet use among adolescents in Europe: demographic and social factors. Addiction. 2012;107(12):2210-22.

[20]Weinstein A, Lejoyeux $M$. Internet addiction or excessive internet use. The American journal of drug and alcohol abuse. 2010;36(5):277-83. 